\title{
Referral Patterns of Outpatient Palliative Care among the Head and Neck Cancer Population
}

\author{
Ari Saravia ${ }^{10}$ Keonho Albert Kong ${ }^{2}$ Ryan Roy ${ }^{1}$ \\ Mary C. Raven ${ }^{4}$ Anna M. Pou ${ }^{6}$ Ashley C. Mays ${ }^{70}$ \\ ${ }^{1}$ Louisiana State University School of Medicine, New Orleans, \\ Louisiana, United States \\ ${ }^{2}$ Department of Otolaryngology, University of North Carolina-Chapel \\ Hill , Chapel Hill, North Carolina USA \\ 3 Barry Ear Nose and Throat. 4212 W Congress St, Suite 1500, \\ Lafayette, Louisiana, USA \\ ${ }^{4}$ Department of Palliative Medicine, Our Lady of the Lake Regional \\ Medical Center, Baton Rouge, Louisiana, United States \\ ${ }^{5}$ Department of Biostatistics, School of Public Health, Louisiana State \\ University Health Sciences Center, New Orleans, Louisiana, United \\ States \\ ${ }^{6}$ Oschner Health System, New Orleans, Louisiana, USA \\ ${ }^{7}$ Department of Otolaryngology, Louisiana State University Health \\ Sciences Center, New Orleans, Louisiana, United States
}

Rachel Barry $^{3} \quad$ Christine Guidry $^{4} \quad$ Lee S. McDaniel ${ }^{5}$

Address for correspondence Ashley C. Mays, MD, LSU Department of Otolaryngology, Head \& Neck Surgical Oncology, Microvascular Reconstruction Our Lady of the Lake Regional Medical Center, 4950 Essen Lane, Ste 400, Baton Rouge, LA 70809, United States (e-mail: amays@Isuhsc.edu).

Int Arch Otorhinolaryngol 2022;26(4):e538-e547.

\section{Abstract \\ Keywords \\ - palliative care \\ - head and neck cancer \\ - pain management \\ - symptom management \\ - resource utilization \\ - advance care planning}

Introduction Patients with head and neck cancer (HNC) experience unique physical and psychosocial challenges that impact their health and quality of life. Early implementation of palliative care has been shown to improve various health care outcomes.

Objective The aim of the present study was to evaluate the patterns of referral of patients with $\mathrm{HNC}$ to outpatient palliative care as they relate to utilization of resources and end-of-life discussions.

Methods We performed a retrospective review of 245 patients with HNC referred to outpatient palliative care services at two Louisiana tertiary care centers from June 1 , 2014 , to October 1, 2019. The control group consisted of those that were referred but did not follow-up. Reasons for referral were obtained, and outcome measures such as emergency department (ED) visits, hospital readmissions, and advance care planning (ACP) documentation were assessed according to predictive variables.

Results There were 177 patients in the treatment group and 68 in the control group. Patients were more likely to follow up to outpatient palliative care services if referred for pain management. Hospital system, prior inpatient palliative care, and number of outpatient visits were associated with an increased likelihood for ED visits and hospital readmissions. Those in the palliative care treatment group were also more likely to have ACP discussions.

Conclusion Early implementation of outpatient palliative care among patients with HNC can initiate ACP discussions. However, there are discrepancies in referral reasons to palliative care and continued existing barriers to its effective utilization. received

June 10, 2021

accepted after revision

September 23, 2021

published online

January 27, 2022
DOI https://doi.org/ $10.1055 / \mathrm{s}-0041-1741436$ ISSN 1809-9777.

\footnotetext{
(c) 2022. Fundação Otorrinolaringologia. All rights reserved.

This is an open access article published by Thieme under the terms of the Creative Commons Attribution-NonDerivative-NonCommercial-License, permitting copying and reproduction so long as the original work is given appropriate credit. Contents may not be used for commercial purposes, or adapted, remixed, transformed or built upon. (https://creativecommons.org/ licenses/by-nc-nd/4.0/) Thieme Revinter Publicações Ltda., Rua do Matoso 170, Rio de Janeiro, RJ, CEP 20270-135, Brazil
} 


\section{Introduction}

Patients with head and neck cancer (HNC) experience many unique challenges due to the sequelae of their condition and treatment. Among their most disturbing symptoms are pain, xerostomia, and dysphagia. ${ }^{1-4}$ Their psychosocial afflictions may include body image issues, poor quality of life, fear of cancer recurrence, depression, anxiety, guilt, self-blame, losing control of daily activities, and feeling like a burden. ${ }^{1,5-8}$ As a result, patients and their caregivers often have a difficult time coping with their condition and the complexities of care work. ${ }^{8-11}$ Beyond the complex, interdisciplinary approach in managing their cancer, a crucial aspect of their quality care involves mitigating the suffering of these patients while also allocating resources effectively. ${ }^{12}$ Patients with a heavy symptom burden due to cancer are more likely to visit emergency rooms ${ }^{13-15}$ and have prolonged hospital stays. ${ }^{16}$ Furthermore, patients with HNC have increased financial expenditures at the end of life due to hospitalizations and treatment, especially those who underutilize hospice services. ${ }^{17,18}$ Early implementation of palliative care services is known to not only improve the value of care by decreasing expenditures among patients with cancer, ${ }^{19-22}$ but also improve their quality of life. ${ }^{3,23}$ However, lack of investment, awareness, and understanding of palliative care services among patients, caregivers, and health care workers are among the barriers to its early implementation at a population-health level. ${ }^{24-27}$ While these services can be provided by various health care workers, the timing and indications for referral to specialty palliative care are still poorly understood. ${ }^{26,27}$ The present study aimed to determine the referral patterns of outpatient palliative care services and how they affect various outcomes among patients with HNC in our affiliated hospital systems.

\section{Methods}

Review and oversight were provided by the Institutional Review Boards of Louisiana State University Health Sciences Center and Our Lady of the Lake Regional Medical Center (OLOL). We performed a retrospective chart review of patients with HNC referred to the outpatient Palliative and Supportive Care clinics at OLOL in Baton Rouge, (private) and University Medical Center (UMC) in New Orleans, Louisiana (public), from June 1st, 2014, to October 1st, 2019. The inclusion criteria were patients aged $\geq 18$ years with an HNC diagnosis and referral to an outpatient palliative care clinic. Patients who were referred but not seen in the palliative care clinic were included as a control group. The reasons why patients did not follow up to outpatient palliative care were collected. The reason for referral was obtained, and it was also noted if the patient had received inpatient palliative care services before referral. Demographic variables were collected, such as age at the time of diagnosis, gender, and race. We used race as a variable to account for systemic racism. ${ }^{28-30}$ We dichotomized race as black and non-black, as these were the two major groups, with the understanding that race is a social construct and is not a biological or genetic explanation for any outcomes. ${ }^{31}$ We collected the amount of substance use, as this is a major public health issue also tied to systemic inequities and is known to worsen health, ${ }^{32}$ especially among the HNC population. ${ }^{33,34}$ Tobacco status was defined as "never," "former," and "current", according to the National Health Interview Survey. ${ }^{35}$ Alcohol status was defined as "none," "light," and "heavy", according to the definition of the National Institute on Alcohol Abuse and Alcoholism (NIAAA). ${ }^{36}$ Additional descriptors determined were the Charlson Comorbidity Index (CCI), to account for medical comorbidities, ${ }^{37,38}$ and the Eastern Cooperative Oncology Group (ECOG) scores, ${ }^{39,40}$ to control for cancer-related performance.

Primary outcome measurements included any emergency department (ED) visits or hospital readmissions after referral to palliative care. The causes of ED visits and hospital readmissions were also assessed. Secondary outcome measurements included the performance of discussions on advance care planning (ACP), referral to hospice services, any time in the intensive care unit (ICU), completion of a do-not-resuscitate (DNR) form, and death in the hospital. Demographic variables were used to stratify the comparison of primary outcomes between the palliative care treatment and control groups, as well as within the treatment group. Analyses based on institution were only performed for primary outcomes, as the number of patients in the public hospital was too small to generate meaningful results for other outcomes. Fisher's exact test was used to calculate odds ratios (OR) with a 95\% confidence interval $(95 \% \mathrm{CI})$. These were calculated with reference to the control group, unless otherwise specified (REF). Values of $p<0.05$ were considered statistically significant. All statistical analyses were performed using the GraphPad Prism (GraphPad Software, Inc., San Diego, CA, US) software, version 9.1.0.

\section{Results}

\section{Patient Characteristics}

Between June 2014 and October 2019, 177 adult patients with HNC were referred to and treated in the outpatient palliative care clinic (palliative care treatment group). The control group consisted of 68 adult patients with HNC who were referred but not seen in the palliative care clinic. Reasons for not following up were available in the records of $48(71 \%)$ of the control group patients, and are listed in - Table 1 , with the most common reasons being no-show $(\mathrm{n}=18 ; 37 \%)$ and treatment refusal $(\mathrm{n}=15 ; 31 \%)$. Patient characteristics are included in - Table 2 . The median age at the time of diagnosis was nearly identical between the treatment and control groups ( 56 and 58 years respectively), and males were more common in both groups ( $\mathrm{n}=125 ; 71 \%$ and $n=46 ; 68 \%$ respectively). There was a higher proportion of black patients in the control group (38\%) compared with the treatment group (28\%). Among the control group, there was a higher proportion of these patients in the public hospital $(\mathrm{n}=8 ; 62 \%)$ compared with the private hospital $(\mathrm{n}=15 ; 29 \%)$. Squamous cell carcinoma was the most 
Table 1 Reasons for no follow-up in the control group $(N=48)$

\begin{tabular}{|l|l|}
\hline Reason & Number (\%) \\
\hline No-show & $18(37)$ \\
\hline Refused treatment & $15(31)$ \\
\hline Referral closed & $5(10)$ \\
\hline Hospice or death & $5(10)$ \\
\hline Good prognosis & $2(4)$ \\
\hline Feeling too ill & $2(4)$ \\
\hline Schedule conflict & $1(2)$ \\
\hline
\end{tabular}

common diagnosis in both groups, with the most common tumor sites being the oropharynx, larynx, and oral cavity. Smoking and alcohol statuses were similarly distributed between the treatment and control groups. The mean $\mathrm{CCI}$ and ECOG scores were comparable between the two study groups. Most patients were treated at OLOL, the private hospital. Inpatient palliative care services before referral were provided to 37 (21\%) patients in the palliative care treatment group and 18 (26\%) in the control group.

The reasons for referral to outpatient palliative care are displayed in - Table 3. Patients in the palliative care treatment group were more likely to have been referred for pain management ( $\mathrm{OR}=18.0$; 95\%CI: 8.06-40.4; $p<0.0001$ ). Patients in the treatment group were less likely to have been referred for symptom management $(O R=0.346$; $95 \%$ CI: $0.195-0.616 ; p<0.001)$ or ACP $(\mathrm{OR}=0.374 ; 95 \% \mathrm{CI}$ : $0.328-0.689 ; p=0.002$ ).

\section{Emergency Department Visits}

Univariate predictors of ED visits are displayed in - Table 4. Among patients aged 56 to 61 years at the time of diagnosis, palliative care treatment was associated with a decreased risk for ED use $(\mathrm{OR}=0.461$; 95\%CI: 0.223 $0.938 ; p=0.047)$. No other age group comparison resulted in a statistically significant outcome ( $p$-values not shown). Referral for pain management was associated with an increased risk for $\mathrm{ED}$ use $(\mathrm{OR}=9.06 ; 95 \% \mathrm{CI}$ : 3.30-24.1; $p<0.0001$ ) among the palliative care treatment group. Conversely, referral for symptom management and ACP were associated with a decreased risk for ED visits (OR $=0.405 ; 95 \% \mathrm{CI}: 0.219-0.762 ; p=0.006$; and $\mathrm{OR}=0.301$; 95\%CI: $0.144-0.665 ; p=0.002$ respectively). Hospital site was not a significant predictor for ED visits. Within the treatment group, having 7 or more outpatient palliative care visits was also associated with an increased risk for ED utilization $(\mathrm{OR}=2.74 ; 95 \% \mathrm{CI}: 1.31-5.75 ; p<0.01)$ compared with fewer visits. The most common causes of ED visits in the treatment group were respiratory issues ( $\mathrm{n}=$ $36 ; 18 \%$ ), weakness ( $n=27 ; 14 \%$ ), and gastrointestinal issues ( $\mathrm{n}=15 ; 7.5 \%$ ). The most common causes for ED visits in the control group were respiratory issues $(\mathrm{n}=12$; $21 \%$ ), gastrointestinal issues ( $\mathrm{n}=7 ; 12 \%$ ), and surgical complications ( $\mathrm{n}=7 ; 12 \%)$. Other causes of ED visits are outlined in - Supplemental Table S1 (online only).
Table 2 Patient characteristics

\begin{tabular}{|c|c|c|}
\hline Variable & Number (\%) & Number (\%) \\
\hline & Palliative care & Control \\
\hline Number of patients & 177 & 68 \\
\hline \multicolumn{3}{|l|}{ Age at diagnosis (years) } \\
\hline Minimum & 29 & 27 \\
\hline $25 \%$ quartile & 49 & 50 \\
\hline Median & 56 & 58 \\
\hline $75 \%$ quartile & 62 & 64 \\
\hline Maximum & 96 & 77 \\
\hline \multicolumn{3}{|l|}{ Tumor site } \\
\hline Oropharynx & $49(28)$ & $17(25)$ \\
\hline Larynx & $45(26)$ & $26(38)$ \\
\hline Oral cavity & $38(22)$ & $18(27)$ \\
\hline Skin & $12(7)$ & $2(3)$ \\
\hline Salivary & $5(3)$ & $1(2)$ \\
\hline Endocrine & $8(5)$ & $1(2)$ \\
\hline Maxilla & $7(4)$ & 0 \\
\hline Skull base & $5(3)$ & $1(2)$ \\
\hline Unknown primary site & $7(4)$ & $2(3)$ \\
\hline \multicolumn{3}{|l|}{ Gender } \\
\hline Male & $125(71)$ & $46(68)$ \\
\hline Female & $52(29)$ & $22(32)$ \\
\hline \multicolumn{3}{|l|}{ Race } \\
\hline Black & $50(28)$ & $26(38)$ \\
\hline Non-black & $127(72)$ & $42(62)$ \\
\hline \multicolumn{3}{|l|}{ Smoking status } \\
\hline Never & $33(19)$ & $8(12)$ \\
\hline Former & $77(44)$ & $38(56)$ \\
\hline Current & $66(38)$ & $22(32)$ \\
\hline \multicolumn{3}{|l|}{ Alcohol status } \\
\hline None & $138(80)$ & $59(88)$ \\
\hline Light & $26(15)$ & $3(5)$ \\
\hline Heavy & $9(5)$ & $5(8)$ \\
\hline $\mathrm{CCl}($ mean $\pm \mathrm{SD})$ & $4.31 \pm 1.98$ & $4.40 \pm 2.11$ \\
\hline ECOG score (mean \pm SD) & $1.87 \pm 0.87$ & $2.27 \pm 0.65$ \\
\hline \multicolumn{3}{|l|}{ Hospital system } \\
\hline OLOL - private & $149(84)$ & $55(81)$ \\
\hline UMC - public & $28(16)$ & $13(19)$ \\
\hline Prereferral IP-PC & $37(21)$ & $18(26)$ \\
\hline \multicolumn{3}{|l|}{ Reason for referral } \\
\hline Pain management & $125(71)$ & $8(12)$ \\
\hline Symptom management & $61(35)$ & $41(60)$ \\
\hline Advance care planning & $35(20)$ & $27(40)$ \\
\hline Goals of care & $18(10)$ & $9(16)$ \\
\hline
\end{tabular}

Abbreviations: $\mathrm{CCl}$, Charlson comorbidity index; ECOG, Eastern Cooperative Oncology Group; IP-PC, inpatient palliative care; OLOL, Our Lady of the Lake Regional Medical Center; SD, standard deviation; UMC, University Medical Center. 
Table 3 Reasons for referral to outpatient palliative care services

\begin{tabular}{|l|l|l|}
\hline Reason & Odds ratio (95\% confidence interval) & $p$-value \\
\hline Pain management & $18.0(8.06-40.4)$ & $<0.0001$ \\
\hline Symptom management & $0.346(0.195-0.616)$ & $<0.001$ \\
\hline Advance care planning & $0.374(0.328-0.689)$ & 0.002 \\
\hline Goals of care & $0.587(0.261-1.32)$ & \\
\hline
\end{tabular}

Note: Odds ratios calculated with reference to the control group.

\section{Hospital Readmissions}

Univariate predictors of hospital readmissions are shown in -Table 5. Referral for pain management was associated with an increased risk for hospital readmissions visits (OR =9.29; 95\%CI: 3.80-24.7; $p<0.0001$ ) among the palliative care treatment group. Referral for ACP was associated with a decreased risk with hospital readmissions $(\mathrm{OR}=0.351 ; 95 \% \mathrm{CI}$ : $0.159-2.86 ; p=0.009)$. No association was found with a referral for symptom management or goals of care. Within the treatment group, patients treated at the public hospital (UMC) were more likely to be readmitted to the hospital $(\mathrm{OR}=2.90 ; 95 \% \mathrm{CI}$ : 1.2-6.99; $p=0.018$ ). Patients who received prior inpatient palliative care services were also more likely to be readmitted to the hospital ( $\mathrm{OR}=2.44 ; 95 \% \mathrm{CI}: 1.14-5.25 ; p=0.022$ ). Moreover, having between 3 and 6 outpatient palliative care visits was associated with an increased risk for a hospital readmission $(\mathrm{OR}=2.26$; $95 \% \mathrm{CI}: 1.09-4.70 ; p=0.029)$. Scheduled procedures were the most common causes for readmissions in the treatment group ( $n=27 ; 17 \%$ ), while gastrointestinal issues were the most common reason in the control group $(n=7$; $16 \%)$. Other causes for hospital re-admissions are outlined in -Supplemental Table S2 (online only).

\section{Secondary Outcomes}

Secondary outcomes are outlined in -Table 6. Patients in the palliative care treatment group were more likely to have ACP discussions. This finding was statistically significant (OR $=2.89$; 95\%CI: $1.59-5.14 ; p<0.001)$. There was no statistically significant difference between the groups in terms of any time in the ICU or hospice referral. A greater proportion of those in the palliative care treatment group had a DNR form completed ( $n=56 ; 32 \%$ versus $n=18 ; 26 \%$ ). A fewer proportion of patients in the palliative care treatment group died in the hospital ( $n=17 ; 8 \%$ versus $n=8 ; 12 \%$ ). Neither variable met statistical significance between the groups $(\mathrm{OR}=1.28 ; 95 \% \mathrm{CI}$ : 0.691-2.37; and $\mathrm{OR}=0.797 ; 95 \% \mathrm{CI}: 0$. $0.3239-1.87$ respectively).

\section{Discussion}

\section{Pain Management}

Patients with HNC face a multitude of challenges regarding their care and well-being. One of their most debilitating symptoms is pain, ${ }^{4}$ which can be nociceptive and neuropathic in quality. ${ }^{41}$ The present study shows that patients with HNC are more likely to follow up with an outpatient palliative care referral if they are being treated for their pain (-Table 3). However, these patients were also more likely to have an ED visit or be hospitalized (- Tables 4-5). This is not surprising, given that pain carries such high morbidity. Previous retrospective studies on HNC patients have also found that the most common reasons for referral to palliative care are pain and symptom management. 2,3,42,43

The most common cause of pain in this population is oral mucositis, often due to radiation and chemotherapy. ${ }^{44,45}$ Mucositis is associated with comorbidities like dysphagia, poor nutritional status, and predisposition to infection-all of which can impact treatment and increase resource utilization. ${ }^{46}$ Predictors of pain among these patients have been described in the past, ${ }^{47,48}$ with consensus agreements emphasizing the correlation of severity to radiation and concurrent systemic therapies. ${ }^{49,50}$ Although pain is difficult to measure objectively, ${ }^{51}$ guidelines recommend frequent assessment of baseline, background, breakthrough, and swallow-related pain in each patient. ${ }^{49}$ It is well known that highdose opioids, despite their common side effects, are frequently needed to manage HNC-related pain. However, since neuropathic pain is still poorly controlled, ${ }^{46,50}$ considerable research has been dedicated to investigating pain-responsive therapies and treatment with a substantial push to reduce opioid use. Recent retrospective studies and a randomized controlled trial have shown that prophylactic gabapentin may be effective at reducing the need for high-dose opioids among the HNC population. ${ }^{52-54}$ Similar randomized controlled trials and subsequent meta-analyses are needed to assess the efficacy of this intervention. Because of this complexity in HNC-related pain, its proper evaluation and management may be well addressed by specialty outpatient palliative care services.

\section{Resource Utilization}

The present study shows that patients with HNC treated by outpatient palliative care tend to have reduced resource utilization depending on the reason for referral. Notably, the control group had more complications from prior surgeries and percutaneous endoscopic gastrostomy (PEG) tube issues leading to ED visits and hospital admissions compared with the treatment group. However, patients who had a high number of outpatient palliative care visits were also more likely to visit the ED or be readmitted to the hospital. This is a finding similar to that of a retrospective study on cancer patients in Sweden, ${ }^{55}$ which showed that those referred to palliative care were more likely to visit the emergency room at least once compared with those not referred. Additionally, we found that prior inpatient palliative cancer services were associated with an increased risk for hospital readmission. 
Table 4 Emergency department visits

\begin{tabular}{|c|c|c|c|c|c|c|}
\hline Variable & Number (\%) & OR $(95 \% \mathrm{Cl})$ & $p$-value & Number (\%) & OR (95\%Cl) & $p$-value \\
\hline & Palliative care & & & Control & & \\
\hline \multicolumn{7}{|l|}{ Age at diagnosis (years) } \\
\hline First quartile (29-48) & $26(15)$ & REF & & $10(15)$ & $0.998(0.446-2.13)$ & \multirow[t]{4}{*}{0.047} \\
\hline Second quartile (49-55) & $22(12)$ & $0.604(0.266-1.45)$ & & $5(7)$ & $1.79(0.680-4.49)$ & \\
\hline Third quartile (56-61) & $22(12)$ & $0.529(0.230-1.23)$ & & $16(24)$ & $0.461(0.223-0.938)$ & \\
\hline Fourth quartile (62-99) & $21(12)$ & $0.485(0.214-1.13)$ & & $6(9)$ & $1.32(0.537-3.32)$ & \\
\hline \multicolumn{7}{|l|}{ Gender } \\
\hline Male & $59(33)$ & REF & & $26(38)$ & $0.808(0.462-1.46)$ & \\
\hline Female & 33 (19) & $1.94(0.997-3.80)$ & & $15(22)$ & $0.809(0.405-1.59)$ & \\
\hline \multicolumn{7}{|l|}{ Race } \\
\hline Black & $30(17)$ & REF & & $25(24)$ & $0.663(0.329-1.28)$ & \\
\hline Non-black & $62(35)$ & $0.636(0.328-1.25)$ & & $16(37)$ & $0.927(0.530-1.69)$ & \\
\hline \multicolumn{7}{|l|}{ Smoking status } \\
\hline Never & $14(8)$ & REF & & $4(6)$ & $1.37(0.452-3.95)$ & \\
\hline Former & $41(23)$ & $1.55(0.708-3.56)$ & & $21(31)$ & $0.675(0.358-1.28)$ & \\
\hline Current & $37(21)$ & $1.73(0.762-4.17)$ & & $16(24)$ & $0.860(0.446-1.63)$ & \\
\hline \multicolumn{7}{|l|}{ Alcohol status } \\
\hline None & $68(38)$ & REF & & $34(50)$ & $0.624(0.363-1.12)$ & \\
\hline Light & $17(10)$ & $1.94(0.837-4.61)$ & & $2(3)$ & $3.51(0.834-15.6)$ & \\
\hline Heavy & $6(3)$ & $2.06(0.544-7.72)$ & & $4(6)$ & $0.561(0.144-1.82)$ & \\
\hline \multicolumn{7}{|l|}{$\mathrm{CCl}$} \\
\hline 2 & $17(10)$ & REF & & $7(10)$ & $0.926(0.375-2.38)$ & \\
\hline 3 & $22(12)$ & $1.08(0.432-2.68)$ & & $8(12)$ & $1.06(0.452-2.39)$ & \\
\hline 4 & $17(10)$ & $0.577(0.230-1.39)$ & & $8(12)$ & $0.797(0.339-1.87)$ & \\
\hline 5 & $8(5)$ & $0.706(0.236-2.41)$ & & $7(10)$ & $0.412(0.141-1.09)$ & \\
\hline $6+$ & $28(16)$ & $1.54(0.631-3.84)$ & & $11(16)$ & $0.974(0.457-2.17)$ & \\
\hline \multicolumn{7}{|l|}{ Hospital system } \\
\hline OLOL - private & $74(42)$ & REF & & $33(49)$ & $0.762(0.427-1.33)$ & \\
\hline UMC - public & $18(10)$ & $1.82(0.768-4.17)$ & & $8(12)$ & $0.849(0.468-1.47)$ & \\
\hline \multicolumn{7}{|l|}{ Prereferral IP-PC } \\
\hline No & $68(38)$ & REF & & $29(43)$ & $0.839(0.468-1.47)$ & \\
\hline Yes & $24(14)$ & $1.93(0.892-3.99)$ & & $12(18)$ & $0.732(0.338-1.56)$ & \\
\hline \multicolumn{7}{|l|}{ Reason for referral } \\
\hline Pain management & $64(36)$ & REF & & $4(6)$ & $9.06(3.30-24.1)$ & $<0.0001$ \\
\hline Symptom management & $32(18)$ & $1.05(0.581-1.90)$ & & $24(35)$ & $0.405(0.219-0.762)$ & 0.006 \\
\hline Advance care planning & $15(8)$ & $0.753(0.358-1.60)$ & & $16(24)$ & $0.301(0.144-0.665)$ & 0.002 \\
\hline Goals of care & $10(6)$ & $1.19(0.460-3.25)$ & & $5(7)$ & $0.754(0.268-2.05)$ & \\
\hline \multicolumn{7}{|l|}{ Postreferral OP-PC visits } \\
\hline $1-2$ & $27(15)$ & REF & \multirow[t]{3}{*}{0.010} & \multirow[t]{3}{*}{$\mathrm{N} / \mathrm{A}$} & \multirow[t]{3}{*}{$\mathrm{N} / \mathrm{A}$} & \\
\hline $3-6$ & $27(15)$ & $1.28(0.605-2.55)$ & & & & \\
\hline $7+$ & $38(21)$ & $2.74(1.28-5.80)$ & & & & \\
\hline
\end{tabular}

Abbreviations: $95 \% \mathrm{Cl}$, 95\% confidence interval; CCI, Charlson comorbidity index; IP-PC, inpatient palliative care; N/A, not avilable; OLOL, Our Lady of the Lake Regional Medical Center; OP-PC, outpatient palliative care; OR, odds ratio; REF, odds ratios calculated with reference to treatment group variable; UMC, University Medical Center. 
Palliative Care for Head and Neck Cancer Saravia et al. 543

Table 5 Hospital readmissions

\begin{tabular}{|c|c|c|c|c|c|c|}
\hline Variable & Number (\%) & OR $(95 \% \mathrm{Cl})$ & $p$-value & Number (\%) & OR $(95 \% \mathrm{Cl})$ & $p$-value \\
\hline & Palliative care & & & Control & & \\
\hline \multicolumn{7}{|l|}{ Age at diagnosis (years) } \\
\hline First quartile (29-48) & $22(12)$ & REF & & $8(12)$ & $1.06(0.452-2.39)$ & \\
\hline Second quartile (49-55) & $23(13)$ & $0.993(0.416-2.36)$ & & $6(9)$ & $1.54(0.591-3.82)$ & \\
\hline Third quartile (56-61) & $24(14)$ & $0.942(0.405-2.17)$ & & $15(22)$ & $0.554(0.272-1.15)$ & \\
\hline Fourth quartile (62-99) & $20(11)$ & $0.664(0.281-1.53)$ & & $8(12)$ & $0.955(0.394-2.18)$ & \\
\hline \multicolumn{7}{|l|}{ Gender } \\
\hline Male & $60(34)$ & REF & & $23(34)$ & $1.00(0.567-1.78)$ & \\
\hline Female & $29(16)$ & $1.37(0.710-2.54)$ & & $14(21)$ & $0.756(0.383-1.58)$ & \\
\hline \multicolumn{7}{|l|}{ Race } \\
\hline Black & $26(15)$ & REF & & 13 (19) & $0.728(0.342-1.46)$ & \\
\hline Non-black & $63(36)$ & $0.909(0.483-1.78)$ & & $24(35)$ & $1.01(0.578-1.78)$ & \\
\hline \multicolumn{7}{|l|}{ Smoking status } \\
\hline Never & $13(7)$ & REF & & $4(6)$ & $1.27(0.404-3.67)$ & \\
\hline Former & $43(24)$ & $1.95(0.872-4.63)$ & & $21(31)$ & $0.718(0.384-1.36)$ & \\
\hline Current & 33 (19) & $1.54(0.675-3.49)$ & & $12(18)$ & $1.07(0.533-2.19)$ & \\
\hline \multicolumn{7}{|l|}{ Alcohol status } \\
\hline None & $64(36)$ & REF & & $31(46)$ & $0.676(0.391-1.18)$ & \\
\hline Light & $17(10)$ & $2.18(0.939-5.16)$ & & $3(4)$ & $2.30(0.697-7.61)$ & \\
\hline Heavy & $7(4)$ & $4.05(0.841-19.7)$ & & $2(3)$ & $1.36(0.290-6.60)$ & \\
\hline \multicolumn{7}{|l|}{$\mathrm{CCl}$} \\
\hline 2 & $16(9)$ & REF & & $6(9)$ & $1.03(0.383-2.68)$ & \\
\hline 3 & $20(11)$ & $1.00(0.404-2.47)$ & & $9(13)$ & $0.835(0.359-2.04)$ & \\
\hline 4 & $22(12)$ & $1.05(0.436-2.52)$ & & $9(13)$ & $0.930(0.412-2.23)$ & \\
\hline 5 & $5(3)$ & $0.385(0.120-1.39)$ & & $6(9)$ & $0.300(0.100-1.07)$ & \\
\hline $6+$ & $26(15)$ & $1.44(0.603-3.52)$ & & $7(10)$ & $1.50(0.632-3.89)$ & \\
\hline \multicolumn{7}{|l|}{ Hospital system } \\
\hline OLOL - private & 69 (39) & REF & \multirow[t]{2}{*}{0.022} & $31(46)$ & $0.762(0.427-1.32)$ & \\
\hline UMC - public & $20(11)$ & $2.90(1.17-6.69)$ & & $6(9)$ & $1.32(0.528-3.32)$ & \\
\hline \multicolumn{7}{|l|}{ Prereferral IP-PC } \\
\hline No & $64(36)$ & REF & \multirow[t]{2}{*}{0.026} & $24(35)$ & $1.04(0.590-1.82)$ & \\
\hline Yes & $25(14)$ & $2.44(1.15-5.28)$ & & $8(12)$ & $1.23(0.542-2.73)$ & \\
\hline \multicolumn{7}{|l|}{ Reason for referral } \\
\hline Pain management & $65(37)$ & REF & & $4(6)$ & $9.29(3.80-24.7)$ & $<0.0001$ \\
\hline Symptom management & $33(19)$ & $1.09(0.593-1.98)$ & & $21(31)$ & $0.513(0.274-0.956)$ & 0.009 \\
\hline Advance care planning & $16(9)$ & $0.777(0.360-1.62)$ & & $15(22)$ & $0.351(0.159-0.789)$ & \\
\hline Goals of care & $10(6)$ & $1.15(0.446-3.14)$ & & $4(6)$ & $0.958(0.309-2.86)$ & \\
\hline \multicolumn{7}{|l|}{ Post-referral OP-PC visits } \\
\hline $1-2$ & $26(15)$ & REF & \multirow[t]{3}{*}{0.044} & \multirow[t]{3}{*}{$\mathrm{N} / \mathrm{A}$} & \multirow[t]{3}{*}{$\mathrm{N} / \mathrm{A}$} & \\
\hline $3-6$ & 34 (19) & $2.26(1.07-4.65)$ & & & & \\
\hline $7+$ & $29(16)$ & $1.51(0.725-3.00)$ & & & & \\
\hline
\end{tabular}

Abbreviations: $95 \% \mathrm{Cl}$, 95\% confidence interval; CCI, Charlson comorbidity index; IP-PC, inpatient palliative care; N/A, not avilable; OLOL, Our Lady of the Lake Regional Medical Center; OP-PC, outpatient palliative care; OR, odds ratio; REF, odds ratios calculated with reference to treatment group variable; UMC, University Medical Center. 
Table 6 Secondary outcomes

\begin{tabular}{|c|c|c|c|c|}
\hline \multirow[t]{2}{*}{ Outcome } & \multicolumn{2}{|l|}{ Number (\%) } & \multirow[t]{2}{*}{ Odds ratio ( $95 \%$ confidence interval) } & \multirow[t]{2}{*}{$p$-value } \\
\hline & Palliative care & Control & & \\
\hline Discussions on advance care planning & $123(66)$ & $30(41)$ & $2.89(1.59-5.14)$ & $<0.001$ \\
\hline Time in Intensive Care Unit & $30(17)$ & $12(18)$ & $0.952(0.466-1.97)$ & \\
\hline Hospice referral & $58(33)$ & $19(28)$ & $1.26(0.686-2.27)$ & \\
\hline Do-not-resuscitate form completed & $56(32)$ & $18(26)$ & $1.28(0.691-2.37)$ & \\
\hline Death in hospital & $17(8)$ & $8(12)$ & $0.797(0.339-1.87)$ & \\
\hline
\end{tabular}

This makes sense, as this patient cohort likely reflects poorer cancer-related performance and overall worse health. Our finding that patients treated in a public hospital (UMC) were more likely to be readmitted compared with those treated in a private one (OLOL) plausibly reflects the former hospital's recency of operations, the population it serves, and the city's systemic inequities worsened by hurricane Katrina in $2005 .^{56}$ This is in concordance with a recent retrospective study on HNC patients ${ }^{15}$ that examined the frequency of ED visits and unplanned hospital visits, which found a strong correlation of these outcomes to care in a public hospital system.

Together, these findings suggest that outpatient palliative care alone is not sufficient to prevent unnecessary ED visits or hospital readmissions among the HNC population. While side-effect monitoring has been proposed as a solution, ${ }^{57}$ we suggest that these disparities could reasonably be diminished by investing in community health workers (CHWs) or patient navigators, health professionals who have a close understanding of the communities they serve. ${ }^{58}$ While there is currently no sustainable funding source for CHWs in Louisiana, their work has been shown to reduce ED use, hospitalizations, and overall health care costs across the country. ${ }^{59-61}$ This is because CHWs address things like timely access to screening programs, health care, health insurance, health education, housing, food security, transportation, and many other social determinants of health. ${ }^{58,62,63}$ Patient-navigator programs for cancer patients have demonstrated their ability to immensely reduce health care costs and lead to better outcomes. ${ }^{59}$ These reasons should prompt the state to develop a sustainable CHW program that could collaborate with palliative care services. This would ensure that its benefits can be expanded to all patients with serious illnesses.

\section{Advance Care Planning}

Our findings also show that patients with HNC treated in an outpatient palliative care clinic increase their likelihood of planning for end-of-life care (-Table $\mathbf{6}$ ). This was despite the most common referral reason being pain management rather than ACP. The value of ACP amongst patients with $\mathrm{HNC}^{6,64}$ and other serious illnesses ${ }^{65}$ has previously been described. The present study suggests that early palliative care referral can initiate ACP discussions regardless of the reason for referral. This can potentially assist in mitigating the emotional and mental burden of end-of-life discussions for patients and their caretakers through the completion of advance directives.

It has been suggested that completion of advance directives alone is not adequate for patients and surrogates to make informed in-the-moment decisions. ${ }^{66}$ However, randomized controlled trials ${ }^{67-69}$ have demonstrated that ACP increases respect for end-of-life wishes, reduces stress and depression among caregivers, and reduces health care utilization at the end of life. A meta-analysis ${ }^{70}$ on the impact of $\mathrm{ACP}$ has shown that it increases the completion of advance directives, end-of-life discussions, and concordance between wishes and treatment, suggesting that these discussionsespecially if held early-are beneficial. Advance care planning is more than just a one-time exercise; it is a continuous dialogue that fosters difficult but honest discussions between the health care team, patients, and caregivers. ${ }^{65}$ Moreover, barriers for ACP can be affected by prognostic uncertainty, illness understanding, worry about dying, systemic racism, culture, religion, spirituality, and family values. $^{65,71-73}$ Effective implementation and utilization of ACP concerning these factors among patients with $\mathrm{HNC}$ require further investigation.

Lastly, while there are benefits when palliative care services are used as a gradual and natural transition in the care of patients with HNC and other serious illnesses, primary providers should not neglect to have meaningful conversations and effective communication with their patients. Primary providers are often better positioned to understand the biopsychosocial challenges their patients face from prior continuity of care. The palliative care specialty workforce cannot yet meet the needs of all patients with $\mathrm{HNC},{ }^{26,74}$ which is why primary providers should train in palliative care and effective communication skills ${ }^{75-77}$ to offer them as an adjunct to the meaningful services they already provide. As clinicians are often pressed for time, these efforts must be supported with health care system restructuring to allow adequate time for these conversations to take place.

The present study has several limitations. As this is an observational study, it reflects inherent bias in the behavior of the patients from the treatment and control groups. Since patients were not matched, we could only examine the differences between those who followed up or not to outpatient palliative care services. For example, patients who follow up with an outpatient appointment could be more likely to utilize other services such as the ED. Neither did we collect other potentially explanatory variables for our 
primary outcomes, such as marital status, tumor staging, PEG-tube status, insurance type, or income. While these would have likely provided additional results, our focus was to examine how the reason for referral to outpatient palliative care affects resource utilization and palliative carerelated outcomes.

\section{Conclusions}

1) Palliative care is known to be beneficial for patients living with serious illnesses, especially HNC, which carries a high symptom burden. The present study demonstrates that outpatient palliative care not only addresses the symptoms of disease, but also leads to earlier, more effective ACP discussions which are crucial for making important end-of-life decisions.

2) However, there are discrepancies in the reasons for referral to outpatient palliative care. This may reflect the high symptom burden related to the pain of the patients who follow up with outpatient palliative care treatment and utilize resources.

3) There remain various barriers to the early utilization of palliative care. Healthcare teams should continue striving to educate themselves, both on their patients' narratives as well as on the benefits of palliative care treatment. Health care systems should invest in palliative medicine as well as CHWs to provide equitable access to appropriate care. This way, the benefits of palliative care can be maximally achieved at a population level.

\section{Conflict of Interests}

The authors have no conflict of interests to declare.

\section{References}

1 Goldstein NE, Genden E, Morrison RS. Palliative care for patients with head and neck cancer: "I would like a quick return to a normal lifestyle”. JAMA 2008;299(15):1818-1825. Doi: 10.1001/ jama.299.15.1818

2 Lal P, Verma M, Kumar G, Shrivastava R, Kumar S. Initial Experience of Head and Neck Cancer Patients Treated in an Oncologist Led Palliative Cancer Care Clinic at a Tertiary Cancer Care Center in Uttar Pradesh: Is the Initiative of a Full-fledged Palliative Care for Cancer Patients Justified. Indian J Palliat Care 2016;22(04): 477-484. Doi: 10.4103/0973-1075.191854

3 Lin C, Kang SY, Donermeyer S, Teknos TN, Wells-Di Gregorio SM. Supportive Care Needs of Patients with Head and Neck Cancer Referred to Palliative Medicine. Otolaryngol Head Neck Surg 2020;163(02):356-363. Doi: 10.1177/0194599820912029

4 Pearman TP, Beaumont JL, Paul D, et al. Evaluation of treatmentand disease-related symptoms in advanced head and neck cancer: validation of the national comprehensive cancer network-functional assessment of cancer therapy-head and neck cancer symptom index-22 (NFHNSI-22). J Pain Symptom Manage 2013;46(01): 113-120. Doi: 10.1016/j.jpainsymman.2012.06.004

5 Ozakinci G, Swash B, Humphris G, Rogers SN, Hulbert-Williams NJ. Fear of cancer recurrence in oral and oropharyngeal cancer patients: An investigation of the clinical encounter. Eur J Cancer Care (Engl) 2018;27(01 Epub20170ct12. Doi: 10.1111/ecc.12785

6 Mott FE, Adams KC. Advance Care Planning and End-of-Life Issues in Head and Neck Cancer. J Palliat Care 2019;34(01):18-20. Doi: $10.1177 / 0825859718788768$
7 Turner J, Kelly B. Emotional dimensions of chronic disease. West J Med 2000;172(02):124-128. Doi: 10.1136/ewjm.172.2.124

8 Kowal J, Wilson KG, McWilliams LA, Péloquin K, Duong D. Selfperceived burden in chronic pain: relevance, prevalence, and predictors. Pain 2012;153(08):1735-1741. Doi: 10.1016/j. pain.2012.05.009

9 Longacre ML, Ridge JA, Burtness BA, Galloway TJ, Fang CY. Psychological functioning of caregivers for head and neck cancer patients. Oral Oncol 2012;48(01):18-25. Doi: 10.1016/j.oraloncology.2011.11.012

10 Penner JL, McClement S, Lobchuk M, Daeninck P. Family members' experiences caring for patients with advanced head and neck cancer receiving tube feeding: a descriptive phenomenological study. J Pain Symptom Manage 2012;44(04):563-571. Doi: 10.1016/j.jpainsymman.2011.10.016

11 Kamal AH, Bausewein C, Casarett DJ, Currow DC, Dudgeon DJ, Higginson IJ. Standards, Guidelines, and Quality Measures for Successful Specialty Palliative Care Integration Into Oncology: Current Approaches and Future Directions. J Clin Oncol 2020;38 (09):987-994. Doi: 10.1200/JCO.18.02440

12 Schenker Y, Arnold RM, Bauman JE, Heron DE, Johnson JT. An enhanced role for palliative care in the multidisciplinary approach to high-risk head and neck cancer. Cancer 2016;122 (03):340-343. Doi: 10.1002/cncr.29754

13 Jairam V, Lee V, Park HS, et al. Treatment-Related Complications of Systemic Therapy and Radiotherapy. JAMA Oncol 2019;5(07): 1028-1035. Doi: 10.1001/jamaoncol.2019.0086

14 Lash RS, Bell JF, Reed SC, et al. A Systematic Review of Emergency Department Use Among Cancer Patients. Cancer Nurs 2017;40 (02):135-144. Doi: 10.1097/NCC.0000000000000360

15 Moore ZR, Pham NL, Shah JL, et al. Risk of Unplanned Hospital Encounters in Patients Treated With Radiotherapy for Head and Neck Squamous Cell Carcinoma. J Pain Symptom Manage 2019;57 (04):738-745.e3. Doi: 10.1016/j.jpainsymman.2018.12.337

16 DeCaria K, Dudgeon D, Green E, et al. Acute care hospitalization near the end of life for cancer patients who die in hospital in Canada. Curr Oncol 2017;24(04):256-261. Doi: 10.3747/ co.24.3704

17 Chen MM, Rosenthal EL, Divi V. End-of-Life Costs and Hospice Utilization in Patients with Head and Neck Cancer. Otolaryngol Head Neck Surg 2019;161(03):439-441. Doi: 10.1177/0194599819846072

18 O'Connor NR, Hu R, Harris PS, Ache K, Casarett DJ. Hospice admissions for cancer in the final days of life: independent predictors and implications for quality measures. J Clin Oncol 2014;32(28):3184-3189. Doi: 10.1200/JCO.2014.55.8817

19 May P, Garrido MM, Cassel JB, et al. Palliative Care Teams' CostSaving Effect Is Larger For Cancer Patients With Higher Numbers Of Comorbidities. Health Aff (Millwood) 2016;35(01):44-53. Doi: 10.1377/hlthaff.2015.0752

20 Lustbader D, Mudra M, Romano C, et al. The Impact of a Home-Based Palliative Care Program in an Accountable Care Organization. J Palliat Med 2017;20(01):23-28. Doi: 10.1089/jpm.2016.0265

21 Sutradhar R, Barbera L, Seow HY. Palliative homecare is associated with reduced high- and low-acuity emergency department visits at the end of life: A population-based cohort study of cancer decedents. Palliat Med 2017;31(05):448-455. Doi: 10.1177/0269216316663508

22 Hjermstad MJ, Kolflaath J, Løkken AO, Hanssen SB, Normann AP, Aass N. Are emergency admissions in palliative cancer care always necessary? Results from a descriptive study. BMJ Open 2013;3 (05):e002515. Doi: 10.1136/bmjopen-2012-002515

23 Temel JS, Greer JA, Muzikansky A, et al. Early palliative care for patients with metastatic non-small-cell lung cancer. N Engl J Med 2010;363(08):733-742. Doi: 10.1056/NEJMoa1000678

24 Zimmermann C, Swami N, Krzyzanowska M, et al. Perceptions of palliative care among patients with advanced cancer and their caregivers. CMAJ 2016;188(10):E217-E227. Doi: 10.1503/ cmaj. 151171 
25 Mcllfatrick S, Noble H, McCorry NK, et al. Exploring public awareness and perceptions of palliative care: a qualitative study. Palliat Med 2014;28(03):273-280. Doi: 10.1177/0269216313502372

26 Check DK, Kaufman BG, Kamal AH, Casarett DJ. Top Ten Tips Palliative Care Clinicians Should Know About Integrating Population Health Principles into Practice. J Palliat Med 2020;23(04): 568-572. Doi: 10.1089/jpm.2020.0100

27 Kamal AH, Wolf S, Nicolla JM, et al. Usability of PCforMe in Patients With Advanced Cancer Referred to Outpatient Palliative Care: Results of a Randomized, Active-Controlled Pilot Trial. J Pain Symptom Manage 2019;58(03):382-389. Doi: 10.1016/j.jpainsymman.2019.05.007

28 Hammonds EM, Reverby SM. Toward a Historically Informed Analysis of Racial Health Disparities Since 1619. Am J Public Health 2019;109(10):1348-1349. Doi: 10.2105/AJPH.2019.305262

29 Hofrichter R, Bhatia R, Eds. 2010Tackling health inequities through public health practice: Theory to action. 2nd ed. A project of the National Association of County and City Health Officials. Oxford University PressNew York, New York

30 Chowkwanyun M, Reed AL Jr. Racial Health Disparities and Covid19 - Caution and Context. N Engl J Med 2020;383(03):201-203. Doi: 10.1056/NEJMp2012910

31 Quest TE, Periyakoil VS, Quill TE, Casarett D. Racial Equity in Palliative Care. J Pain Symptom Manage 2021;61(03):435-437. Doi: 10.1016/j.jpainsymman.2020.12.005

32 Rehm J. The risks associated with alcohol use and alcoholism. Alcohol Res Health 2011;34(02):135-143

33 Maier H, Dietz A, Gewelke U, Heller WD, Weidauer H. Tobacco and alcohol and the risk of head and neck cancer. Clin Investig 1992;70 (3-4):320-327. Doi: 10.1007/BF00184668

34 Freedman ND, Schatzkin A, Leitzmann MF, Hollenbeck AR, Abnet CC. Alcohol and head and neck cancer risk in a prospective study. Br J Cancer 2007;96(09):1469-1474. Doi: 10.1038/sj.bjc.6603713

35 NHIS - Adult Tobacco Use - Glossary. Centers for Disease Control and Prevention; 2017

36 Drinking Levels Defined. National Institute on Alcohol Abuse and Alcoholism; 2021

37 Charlson ME, Pompei P, Ales KL, MacKenzie CR. A new method of classifying prognostic comorbidity in longitudinal studies: development and validation. J Chronic Dis 1987;40(05):373-383. Doi: 10.1016/0021-9681(87)90171-8

38 Quan H, Li B, Couris CM, et al. Updating and validating the Charlson comorbidity index and score for risk adjustment in hospital discharge abstracts using data from 6 countries. Am J Epidemiol 2011;173(06):676-682. Doi: 10.1093/aje/kwq433

39 Oken MM, Creech RH, Tormey DC, et al. Toxicity and response criteria of the Eastern Cooperative Oncology Group. Am J Clin Oncol 1982;5(06):649-655

40 Buccheri G, Ferrigno D, Tamburini M. Karnofsky and ECOG performance status scoring in lung cancer: a prospective, longitudinal study of 536 patients from a single institution. Eur J Cancer 1996;32A(07):1135-1141. Doi: 10.1016/0959-8049(95) 00664-8

41 Epstein JB, Wilkie DJ, Fischer DJ, Kim YO, Villines D. Neuropathic and nociceptive pain in head and neck cancer patients receiving radiation therapy. Head Neck Oncol 2009;1:26. Doi: 10.1186/1758-3284-1-26

42 Nikoloudi M, Lymvaios I, Zygogianni A, et al. Quality of Life, Anxiety, and Depression in the Head-and-Neck Cancer Patients, Undergoing Intensity-Modulated Radiotherapy Treatment. Indian J Palliat Care 2020;26(01):54-59. Doi: 10.4103/IJPC. IJPC_168_19

43 Ethunandan M, Rennie A, Hoffman G, Morey PJ, Brennan PA. Quality of dying in head and neck cancer patients: a retrospective analysis of potential indicators of care. Oral Surg Oral Med Oral Pathol Oral Radiol Endod 2005;100(02):147-152. Doi: 10.1016/j. tripleo.2004.11.011
44 Eilers J, Harris D, Henry K, Johnson LA. Evidence-based interventions for cancer treatment-related mucositis: putting evidence into practice. Clin J Oncol Nurs 2014;18(Suppl):80-96. Doi: 10.1188/14.CJON.S3.80-96

45 Bossi P, Giusti R, Tarsitano A, et al. The point of pain in head and neck cancer. Crit Rev Oncol Hematol 2019;138:51-59. Doi: 10.1016/j.critrevonc.2019.04.001

46 Murphy BA, Beaumont JL, Isitt J, et al. Mucositis-related morbidity and resource utilization in head and neck cancer patients receiving radiation therapy with or without chemotherapy. J Pain Symptom Manage 2009;38(04):522-532. Doi: 10.1016/j.jpainsymman.2008.12.004

47 Shuman AG, Terrell JE, Light E, et al. Predictors of pain among patients with head and neck cancer. Arch Otolaryngol Head Neck Surg 2012;138(12):1147-1154. Doi: 10.1001/jamaoto.2013.853

48 McMenamin EM, Grant M. Pain Prevention Using Head and Neck Cancer as a Model. J Adv Pract Oncol 2015;6(01):44-49

49 Mirabile A, Airoldi M, Ripamonti C, et al. Pain management in head and neck cancer patients undergoing chemo-radiotherapy: Clinical practical recommendations. Crit Rev Oncol Hematol 2016;99:100-106. Doi: 10.1016/j.critrevonc.2015.11.010

50 Sroussi HY, Epstein JB, Bensadoun RJ, et al. Common oral complications of head and neck cancer radiation therapy: mucositis, infections, saliva change, fibrosis, sensory dysfunctions, dental caries, periodontal disease, and osteoradionecrosis. Cancer Med 2017;6(12):2918-2931. Doi: 10.1002/cam4.1221

51 Wagemakers SH, van der Velden JM, Gerlich AS, Hindriks-Keegstra AW, van Dijk JFM, Verhoeff JJC. A Systematic Review of Devices and Techniques that Objectively Measure Patients' Pain. Pain Physician 2019;22(01):1-13

52 Bar Ad V, Weinstein G, Dutta PR, et al. Gabapentin for the treatment of pain syndrome related to radiation-induced mucositis in patients with head and neck cancer treated with concurrent chemoradiotherapy. Cancer 2010;116(17):4206-4213. Doi: $10.1002 /$ cncr.25274

53 Milazzo-Kiedaisch CA, Itano J, Dutta PR. Role of Gabapentin in Managing Mucositis Pain in Patients Undergoing Radiation Therapy to the Head and Neck. Clin J Oncol Nurs 2016;20(06): 623-628. Doi: 10.1188/16.CJON.623-628 Erratum in: Vol. 21, No. 1, p. 33. PMID: 27857262; PMCID: PMC5621478

54 Hermann GM, Iovoli AJ, Platek AJ, et al. A single-institution, randomized, pilot study evaluating the efficacy of gabapentin and methadone for patients undergoing chemoradiation for head and neck squamous cell cancer. Cancer 2020;126(07):1480-1491. Doi: $10.1002 / \mathrm{cncr} .32676$

55 Ullgren H, Kirkpatrick L, Kilpeläinen S, Sharp L. Working in silos? Head \& Neck cancer patients during and after treatment with or without early palliative care referral. Eur J Oncol Nurs 2017; 26:56-62. Doi: 10.1016/j.ejon.2016.12.003

56 Rudowitz R, Rowland D, Shartzer A. Health care in New Orleans before and after Hurricane Katrina. Health Aff (Millwood) 2006; 25(05):w393-w406. Doi: 10.1377/hlthaff.25.w393

57 Warrington L, Absolom K, Conner M, et al. Electronic Systems for Patients to Report and Manage Side Effects of Cancer Treatment: Systematic Review. J Med Internet Res 2019;21(01):e10875. Doi: $10.2196 / 10875$

58 Sugarman M, Ezouah P, Haywood C, Wennerstrom A. Promoting Community Health Worker Leadership in Policy Development: Results from a Louisiana Workforce Study. J Community Health 2021;46(01):64-74. Doi: 10.1007/s10900-020-00843-7

59 Rocque GB, Pisu M, Jackson BE, et al; Patient Care Connect Group. Resource Use and Medicare Costs During Lay Navigation for Geriatric Patients With Cancer. JAMA Oncol 2017;3(06): 817-825. Doi: 10.1001/jamaoncol.2016.6307

60 Enard KR, Ganelin DM. Reducing preventable emergency department utilization and costs by using community health workers as patient navigators. J Healthc Manag 2013;58(06):412-427, discussion 428 
Palliative Care for Head and Neck Cancer Saravia et al. 547

61 Jack HE, Arabadjis SD, Sun L, Sullivan EE, Phillips RS. Impact of Community Health Workers on Use of Healthcare Services in the United States: A Systematic Review. J Gen Intern Med 2017;32 (03):325-344. Doi: 10.1007/s11606-016-3922-9

62 Roland KB, Milliken EL, Rohan EA, et al. Use of Community Health Workers and Patient Navigators to Improve Cancer Outcomes Among Patients Served by Federally Qualified Health Centers: A Systematic Literature Review. Health Equity 2017;1(01):61-76. Doi: 10.1089/heq.2017.0001

63 Braun R, Catalani C, Wimbush J, Israelski D. Community health workers and mobile technology: a systematic review of the literature. PLoS One 2013;8(06):e65772. Doi: 10.1371/journal. pone.0065772

64 Shuman AG, Yang Y, Taylor JM, Prince ME. End-of-life care among head and neck cancer patients. Otolaryngol Head Neck Surg 2011; 144(05):733-739. Doi: 10.1177/0194599810397603

65 Hall A, Rowland C, Grande G. How Should End-of-Life Advance Care Planning Discussions Be Implemented According to Patients and Informal Carers? A Qualitative Review of Reviews. J Pain Symptom Manage 2019;58(02):311-335. Doi: 10.1016/j.jpainsymman.2019.04.013

66 Sudore RL, Fried TR. Redefining the "planning" in advance care planning: preparing for end-of-life decision making. Ann Intern Med 2010;153(04):256-261. Doi: 10.7326/0003-4819-153-4201008170-00008

67 Teno JM, Gruneir A, Schwartz Z, Nanda A, Wetle T. Association between advance directives and quality of end-of-life care: a national study. J Am Geriatr Soc 2007;55(02):189-194. Doi: 10.1111/j.1532-5415.2007.01045.x

68 Detering KM, Hancock AD, Reade MC, Silvester W. The impact of advance care planning on end of life care in elderly patients: randomised controlled trial. BMJ 2010;340:c1345. Doi: 10.1136/bmj.c1345

69 Molloy DW, Guyatt GH, Russo R, et al. Systematic implementation of an advance directive program in nursing homes: a randomized controlled trial. JAMA 2000;283(11):1437-1444. Doi: 10.1001/ jama.283.11.1437

70 Houben CHM, Spruit MA, Groenen MTJ, Wouters EFM, Janssen DJA. Efficacy of advance care planning: a systematic review and meta-analysis. J Am Med Dir Assoc 2014;15(07):477-489. Doi: 10.1016/j.jamda.2014.01.008

71 Yoo SH, Lee J, Kang JH, et al. Association of illness understanding with advance care planning and end-of-life care preferences for advanced cancer patients and their family members. Support Care Cancer 2020;28(06):2959-2967. Doi: 10.1007/s00520-01905174-5

72 Rodenbach RA, Althouse AD, Schenker Y, et al. Relationships Between Advanced Cancer Patients' Worry About Dying and Illness Understanding, Treatment Preferences, and Advance Care Planning. J Pain Symptom Manage 2021;61(04):723-731. e1. Doi: 10.1016/j.jpainsymman.2020.09.004

73 Lund S, Richardson A, May C. Barriers to advance care planning at the end of life: an explanatory systematic review of implementation studies. PLoS One 2015;10(02):e0116629. Doi: 10.1371/ journal.pone.0116629

74 Lu-Myers Y. Training Otolaryngologists in Palliative Care Delivery: An Underutilized Opportunity. Otolaryngol Head Neck Surg 2018; 158(01):24-26. Doi: 10.1177/0194599817735314

75 Back AL, Fromme EK, Meier DE. Training Clinicians with Communication Skills Needed to Match Medical Treatments to Patient Values. J Am Geriatr Soc 2019;67(S2):S435-S441. Doi: 10.1111/ jgs.15709

76 Kruser JM, Taylor LJ, Campbell TC, et al. "Best Case/Worst Case": Training Surgeons to Use a Novel Communication Tool for HighRisk Acute Surgical Problems. J Pain Symptom Manage 2017;53 (04):711-719.e5. Doi: 10.1016/j.jpainsymman.2016.11.014

77 National Coalition for Hospice and Palliative Care. Clinical practice guidelines for quality palliative care, 4 th edition. Richmond, VA: National Coalition for Hospice and Palliative Care; 2018 